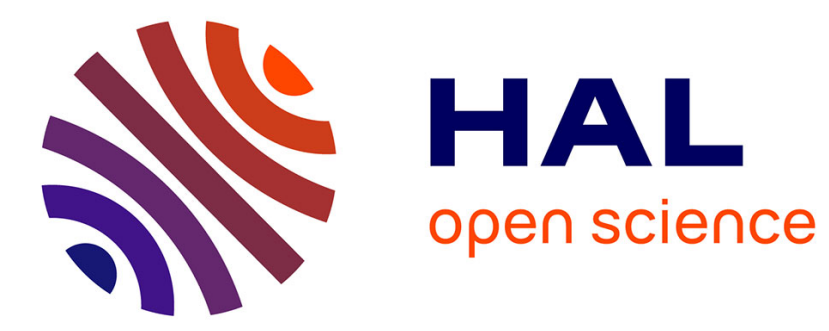

\title{
The super-excess energy dissipation in diatom algae: comparative analysis with higher plants
}

\author{
Alexander V. Ruban, Johann Lavaud, Bernard Rousseau, Gerard Guglielmi, \\ Peter Horton, Anne-Lise Etienne
}

\section{- To cite this version:}

Alexander V. Ruban, Johann Lavaud, Bernard Rousseau, Gerard Guglielmi, Peter Horton, et al.. The super-excess energy dissipation in diatom algae: comparative analysis with higher plants. Photosynthesis Research, 2004, 82, pp.165-175. 10.1007/s11120-004-1456-1 . hal-01094393

\section{HAL Id: hal-01094393 https://hal.science/hal-01094393}

Submitted on 16 Dec 2014

HAL is a multi-disciplinary open access archive for the deposit and dissemination of scientific research documents, whether they are published or not. The documents may come from teaching and research institutions in France or abroad, or from public or private research centers.
L'archive ouverte pluridisciplinaire HAL, est destinée au dépôt et à la diffusion de documents scientifiques de niveau recherche, publiés ou non, émanant des établissements d'enseignement et de recherche français ou étrangers, des laboratoires publics ou privés. 
Photoprotection in Diatom Algae

Regular Paper

The super-excess energy dissipation in diatom algae: comparative analysis with higher plants

Alexander V. Ruban ${ }^{\star}{ }^{*}$, Johann Lavaud $^{\wedge}$, Bernard Rousseau^${ }^{\wedge}$ Gerard Guglielmi^${ }^{\wedge}$, Peter Horton $^{\&}$ and Anne-Lise Etienne ${ }^{\wedge}$

${ }^{\star}$ The Robert Hill Institute, Department of Molecular Biology and Biotechnology, University of Sheffield, UK

^ Organismes Photosynthétiques et Environnement, FRE 2433 CNRS, Département de Biologie, ENS 46 rue d'Ulm, 75230 Paris cedex 05, France

Corresponding author:

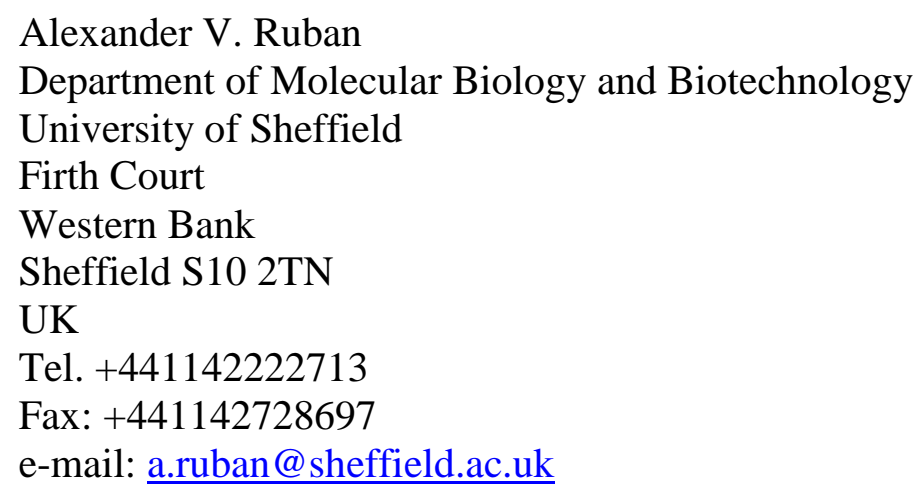




\section{Abstract}

When grown at intermittent light regime, diatom alga Phaeodactylum tricornutum is able to form photoprotective non-photochemical fluorescence quenching (NPQ) 3 - 5 times larger than that observed in the higher plants. This quenching is sustained in the dark for 5-10 min, reverses completely within approx. $1 \mathrm{hr}$ and seems to be very tightly related to the presence of the zeaxanthin analogue, diatoxanthin. Addition of the uncoupler $\mathrm{NH}_{4} \mathrm{Cl}$ before illumination can completely abolish formation of NPQ, revealing the $\Delta \mathrm{pH}$-dependency of the xanthophyll cycle activity. Once established, NPQ can also be almost completely reversed by the uncoupler. However the higher NPQ is formed the more time is required for its reversal. At the point when the fluorescence was approx. $90 \%$ recovered the level of illumination-induced diatoxanthin was found to be only partially reduced. This indicates that the proton gradient is a key triggering factor of NPQ. It was also noticed that NPQ in Phaeodactylum cells was absent even when majority of reaction centers were closed and the plastoquinone pool was significantly reduced. The absence of NPQ at these conditions could be due to very low levels of $\Delta \mathrm{pH}$. It is likely that in diatoms alternative sources of protons such as the PSI cyclic electron transfer and/or chlororespiration are important in generating the proton gradient sufficient to trigger NPQ. Absorption changes associated with the xanthophyll cycle activity were found to be larger than those for higher plants. The position of the positive maximum in the difference spectrum illuminated-minus-dark was $512-514 \mathrm{~nm}$ in comparison to the $505-508 \mathrm{~nm}$ for leaves. The $535 \mathrm{~nm}$ band associated with NPQ in plants is absent in Phaeodactylum. An uncoupler-sensitive absorption change at $522 \mathrm{~nm}$ was discovered. Kinetics of NPQ showed linear correlation with the $522 \mathrm{~nm}$ absorption change. 


\section{Key words}

Chlorophyll fluorescence; nonphotochemical fluorescence quenching; absorption spectra; diatoms; Phaeodactylum tricornutum; xanthophyll cycle; diatoxanthin

\section{Abbreviations}

NPQ - Nonphotochemical chlorophyll fluorescence quenching; PSII - Photosystem

II; DT - diatoxanthin; LHC - light-harvesting complex; DD - diadinoxanthin; PSI Photosystem I 


\section{Introduction}

Diatom algae are dominant phytoplankton component in the vast areas of cold waters of the North Atlantic and Arctic Oceans. They contribute to almost $25 \%$ of the primary photosynthetic production on Earth and therefore play an important role in the energy balance of our biosphere (Treguer at al. 1995, Field at al. 1998, Smetacek 1999). It is widely known that the photosynthetic efficiency is dependent upon the light environment - too much light can be dangerous for photosynthesis, in particular to the photosystem II (PSII). At conditions of excess light the most powerful oxidant in nature, PSII reaction center, can cause a fatal damage to this photosystem and subsequent decrease in the photosynthetic efficiency (Osmond, 1981, Horton and Ruban, 1992, Barber, 1995). However, a mechanism does exist to minimise this effect by safely dissipating excess of harmful energy into heat. This process can be monitored by measuring nonphotochemical chlorophyll fluorescence quenching (NPQ) - an indicator of the nonradiative excitation energy dissipation in the photosynthetic antenna (Krause and Weis, 1991). The mechanism of NPQ was a subject of intense research in higher plants (Demmig-Adams B and Adams III, 1992, Horton et al., 1996, Niyogi, 1999). So far it is established that it occurs in light harvesting system of PSII, triggered by $\Delta \mathrm{pH}$ and modulated by xanthophylls (Horton et al., 1996, Gilmore, 1997). Recently a PSII protein PsbS was discovered to be a key factor sensing $\Delta \mathrm{pH}$ ( $\mathrm{Li}$ et al., 2000, 2002, 2002b, 2002c), binding zeaxanthin (Aspinall-O'Dea et al., 2002) and probably triggering the conformational changes within PSII antenna (Horton et al., 2000), which leads to its transition into the dissipative mode. The physical nature of this quenching is still under debate. There exist two major theories. One implies that zeaxanthin is a direct quencher of the chlorophyll excited state (Demmig-Adams, 1990, Owens et al., 1992, Frank et al., 
1994, Gilmore, 1997). The other theory suggests that the quencher is a chlorophyll dimer or excimer formed during the antenna conformational transition assisted by zeaxanthin as an allosteric activator (Horton et al. 2000). Diatom algae possess the capacity for energy dissipation, which in some cases exceeds that of the higher plants. (Ting and Owens, 1993, Arsalane et al., 1994, Olaizola et al., 1994, Casper-Lindley and Bjorkman, 1998). Recently an unusually high NPQ (almost twice the level of control) was found in Phaeodactylum tricornutum cells grown under intermittent light regime (Lavaud et al., 2002a, b). This model alga possesses more than 5 times capacity to dissipate excess energy as compared to higher plants. NPQ is dependent on the build-up of a transthylakoid proton gradient and on xanthophyll cycle activity. This cycle is different from violaxanthin cycle because different xanthophylls, diadinoxanthin (DD) and diathoxanthin (DT), represent it. Also it is a one-step process: deepoxidation of only one oxygen takes place changing the number of conjugated double bonds from 10 to 11 , which equals to antheraxanthin-zeaxanthin conversion (Hager and Stransky, 1970). It is interesting to note that the intermittent light regime had no large effects on the pigment composition and antenna size of Phaeodactylum apart from the dramatic increase in the xanthophyll pool size (Lavaud et al., 2002a, 2003). At these conditions exceptionally large levels of NPQ have been recorded. In this study we focus on investigation of the relationship between DT concentration, $\Delta \mathrm{pH}$ and NPQ in diatom algae using uncouplers and simultaneous kinetic measurements of NPQ and DT formation. We show in the present report that the free DT is unlikely to be the fluorescence quencher. It has to undergo $\Delta \mathrm{pH}$ dependent incorporation/activation into the quenching locus. Since the concentration of DT is often larger than that of zeaxanthin in plants and the maximum deepoxidation capacities are similar it is possible that more DT is involved in the 
fluorescence quenching than zeaxanthin. All data indicate that the differences between composition and organisation of light-harvesting complex (LHC) of plants and diatoms may be central in determining the NPQ capacity. We have found a new absorption change at $522 \mathrm{~nm}$, which linearly correlates with NPQ and is possibly associated with DT activation in the quenching locus. For understanding of the excess energy dissipation mechanism, comparison with higher plants is essential since diatoms having different xanthophylls and different antenna system, containing specific polypeptides and pigment populations, possess an effective NPQ with mechanistic features similar to that of plants.

\section{Materials and Methods}

\section{Material}

Phaeodactylum tricornutum cells were grown photoautotrophically in sterile natural seawater as described in (Lavaud et al., 2002a). Briefly, cultures were incubated at $18{ }^{\circ} \mathrm{C}$ in airlifts continuously flushed with air. They were grown under a white light intensity of $40 \mu \mathrm{mol}$ photons $\mathrm{m}^{-2} \mathrm{~s}^{-1}$ provided by fluorescent tubes (Claude, Blanc Industry, France) with a 5 min light/55 min dark cycle. Cells were collected after 30-40 days still in their exponential growth phase, since the growth rate under the intermittent light regime is extremely low. Part of the culture was then diluted in fresh medium to maintain cells in exponential growth phase. Arabidopsis taliana cv Columbia plants were grown in growth chambers at $8 \mathrm{hrs}$ photoperiod and $200 \mu \mathrm{M}$ quanta $\mathrm{m}^{-2} \mathrm{~s}^{-1}$ for 8 weeks.

\section{Thylakoid preparations and treatments}

Thylakoids were prepared either from dark-adapted $(1 \mathrm{hr}$ after the end of $5 \mathrm{~min}$ illumination period) or illuminated (5000 $\mu \mathrm{mol}$ photons $\mathrm{m}^{-2} \mathrm{~s}^{-1}$ for $\left.25 \mathrm{~min}\right)$ algae. Cells 
were broken in a standard buffer used for spinach thylakoid preparation (Ruban et al., 1999) by 3 cycles of French press treatment and centrifugation. In this procedure thylakoids were released from approx. $90 \%$ of all cells. Final step included peletting of thylakoids and resuspending in the medium, which contained $0.35 \mathrm{M}$ sorbitol, $1 \mathrm{mM}$ EDTA, $5 \mathrm{mM} \mathrm{MgCl} 2$ and $50 \mathrm{mM}$ HEPES. All handling of material was carried out in a dark room. The diadinoxanthin de-epoxidation was carried out at pH5.5 for $1 \mathrm{hr}$ at chlorophyll concentration of $50 \mu \mathrm{M}$ in $200 \mathrm{ml}$ of medium with the constant stirring at room temperature. Intact spinach chloroplasts were prepared as described earlier (Ruban and Horton, 1999). LHC from algae was prepared using solubilisation of dark-adapted and low-pH-treated thylakoid membranes with digitonin for $1 \mathrm{hr}$ on ice and subsequent sucrose gradient centrifugation at $200000 \mathrm{~g}$ for $18 \mathrm{hrs}$ (for more details see Lavaud et al., 2003).

\section{Pigment analysis}

Pigment analyses were performed using HPLC as described previously (Arsalene et al., 1994, Lavaud et al., 2003). Pigments were extracted by a phase separation procedure: samples were first mixed with a methanol:acetone (50:50, 1 volume) solution completed with ether (1 volume) and water- $\mathrm{NaCl} 10 \%$ (2 volumes). Deepoxidation state index was calculated as: $\mathrm{DES}=(\mathrm{DT}) /((\mathrm{DD})+(\mathrm{DT}))$, where $(\mathrm{DT})$ and $(\mathrm{DD})$ are concentrations of diatoxanthin and diadinoxanthin, respectively.

\section{Chlorophyll fluorescence measurements}

Chlorophyll fluorescence traces were measured using PAM-101 Walz fluorometer (Walz, Effeltrich, Germany) and a standard thermostatic cell for liquid samples as described by Lavaud et al. (Lavaud et al., 2002a). NPQ was calculated as $\left(F_{m^{-}}\right.$ $\left.F_{m}{ }^{\prime}\right) / F_{m}{ }^{\prime} \cdot q P$ was calculated as $\left(F_{m}{ }^{\prime}-F s\right) /\left(F_{m}{ }^{\prime}-F_{o}{ }^{\prime}\right) . F_{m}$ and $F_{m}{ }^{\prime}$ are the maximum 
levels of fluorescence before and during actinic illumination, respectively. $F_{s}$ is the steady-state fluorescence level. $F_{o}{ }^{\prime}$ is the dark level of fluorescence measured immediately after switching off the actinic light. The saturating white light pulse intensity was $6000 \mu \mathrm{mol}$ photons $\mathrm{m}^{-2} \mathrm{~s}^{-1}$.

\section{Absorption measurements}

Absorption spectra and simultaneous chlorophyll fluorescence and absorption kinetics in the 505-522 $\mathrm{nm}$ region were measured using DW2000 Aminco Spectrophotometer (American Instrument Co., USA) in a single or double beam mode. Spectral resolution was $0.5 \mathrm{~nm}$ and $2 \mathrm{~nm}$ for stationary and kinetic measurements, respectively. To induce absorption changes, sample was illuminated at $90^{\circ}$ with respect to the measuring beam. For illumination a $150 \mathrm{~W}$ tungsten halogen bulb light filtered by RG610 Schott filter, transmitting efficiently above $610 \mathrm{~nm}$, (Optical Glass Inc., USA) was used. To protect the photomultiplier from actinic light a combination of Corning 4-96 and OCL1 Cyan T400-570 filters, transmitting in the region of 400$570 \mathrm{~nm}$ was used (Corning Co, USA). The actinic light intensity was $700 \mu \mathrm{mol}$ photons $\mathrm{m}^{-2 \cdot} \mathrm{s}^{-1}$

\section{Results and Discussion}

$N P Q$ induction and reversibility in diatoms in comparison to higher plants

Figure 1 shows typical traces of chlorophyll $a$ fluorescence quenching induced by continuous illumination of Phaeodactylum cells (A) and Arabidopsis leaves (B). The actinic light intensity was close to saturate PSII electron transport for the both types of material. For the algae the saturating light intensity was almost 4 times lower than that

for Arabidopsis leaves (500-700 and 2000-2500 $\mu \mathrm{mol}$ photons $\mathrm{m}^{-2} \cdot \mathrm{s}^{-1}$ respectively). In 
Phaeodactylum fluorescence was quenched quickly and almost monophasically. The fluorescence level went far below the $\mathrm{F}_{\mathrm{o}}$ and the total NPQ reached as far as 9 in some cases after only 5 min of illumination. In plants, fluorescence decrease was less intense (NPQ only 1.9 - 2.1) and more complex with a visible slow phase. The slow phase was similar to the previously observed fluorescence quenching induction in spinach leaves and attributed to the gradual formation of zeaxanthin (Ruban and Horton, 1999). Removal of actinic illumination caused fast relaxation of the fluorescence level in leaves, whereas in diatoms fluorescence remained completely quenched during 5-10 minutes of dark-adaptation. It took almost 50 minutes to restore the $\mathrm{F}_{\mathrm{m}}$ in Phaeodactylum. The second illumination cycle showed much faster fluorescence quenching in leaves, but not in diatoms, where the rate of quenching was almost the same as during the first illumination cycle. It is worth to notice that the fluorescence relaxation in Arabidopsis leaves after the second illumination phase was almost $50 \%$ slower than the recovery after the first illumination phase but still much faster than that in diatoms. NPQ after the second phase was increased to $2.6-2.8$, which is due to additional zeaxanthin formation (Ruban and Horton, 1999, Ruban, unpublished). As was noticed earlier in experiments on isolated chloroplasts the presence of zeaxanthin enhances not only NPQ but also the time required for its relaxation (Rees et al., 1989). In diatoms grown under intermittent light regime xanthophyll cycle pool size is almost doubled comparing to control cells (Lavaud et al., 2002a,b, 2003). There are minimum 2 diadinoxanthin molecules per LHC monomer in cells grown under intermittent light regime (Lavaud et al., 2003). That is twice the maximum amount of violaxanthin found in LHCII of plants (Ruban et al., 1999). This could cause an increase in relaxation time in agreement with the observations made on plants. Hence, the tendency for large NPQ to reverse slowly 
seems to be a common feature for plants and diatoms. To explore further the relationship between the extent of NPQ and the extent of its recovery and rate in diatoms varying periods of actinic light illumination were employed to modulate the amount of quenching. Figure 2 shows the results of this approach. Indeed, fluorescence level was almost restored within 5 min of dark adaptation following the illumination when the NPQ level was small. The proportion of reversible quenching (restored after $5 \mathrm{~min}$ ) was becoming smaller with the increase of the illumination time and NPQ respectively.

\section{Effect of an uncoupler on the $N P Q$ relaxation}

To find if the slow relaxation of NPQ is linked to the sustained $\Delta \mathrm{pH}$ and protonation of the quenching locus, we employed ammonium chloride $\left(\mathrm{NH}_{4} \mathrm{Cl}\right)$ as an uncoupler. When $\mathrm{NH}_{4} \mathrm{Cl}$ is added before the illumination NPQ can be completely inhibited (Figure $3 \mathrm{~A}$, trace 1), indicating efficient permeability of the uncoupler into the algal chloroplast (Lavaud et al, 2002b). Figure 3B shows typical rapid fluorescence level recovery upon addition of uncoupler to isolated intact chloroplasts. The effect of $\mathrm{NH}_{4} \mathrm{Cl}$ on the NPQ in diatoms is very different. When added at different stages of NPQ formation in diatoms, $\mathrm{NH}_{4} \mathrm{Cl}$ reverses promptly the fluorescence level when NPQ is within the range of that observed in plants (Figure $3 \mathrm{~A}$, traces 2-3). But it is clear that the reversal becomes much slower for larger values of NPQ. For NPQ values up to 1.7- 2.0 the level of diatoxanthin was decreased during $5 \mathrm{~min}$ after addition of uncoupler only by $20 \%$. When the quenching level approached 3 and above, the NPQ relaxation time started to rise dramatically (Figure 4) as well as the extent of DT epoxidation (not shown). For NPQ level around 6 the relaxation time of NPQ became close to 15 minutes. For the same duration of dark recovery more DT 
was found to be re-epoxidised in the presence of $\mathrm{NH}_{4} \mathrm{Cl}$ than in the control. This observation suggests that $\mathrm{NH}_{4} \mathrm{Cl}$ has accelerated not only the reversibility of NPQ but also the rate of diatoxanthin epoxidation, since the dark adaptation time required to epoxidise completely diatoxanthin at this level of NPQ was found to be more than 30 min (Lavaud at al., 2002b). These results raised a few important mechanistic and physiological issues. DT is certainly not the only factor that controls NPQ - proton gradient and protonation are essential triggers of it, as was suggested earlier (Lavaud et al., 2002b). It is possible that after illumination a residual level of $\Delta \mathrm{pH}$ still remains and is sufficient to sustain high level of NPQ in darkness and the presence of DT. The chlororespiration could be an important factor contributing to the proton gradient in diatoms (Jakob et al., 1999, Lavaud et al., 2002c). This situation was observed in some higher plant species (Ruban and Horton, 1995), particularly under conditions of combined light and cold stress (Verhoeven et al., 1998). Indeed, comparing the data on spontaneous (Figure 1) and uncoupler-dependent recovery of NPQ (Figure 3), it is feasible to conclude that the uncoupler accelerates the slow release of protons out of the quenching locus. Though being not the most lypophilic agent, $\mathrm{NH}_{4} \mathrm{Cl}$ is still effective to prevent NPQ. Trials to employ more lipophilic uncoupler nigericin have failed, since it was not able to diffuse through the cell wall (not shown). However, the addition of $\mathrm{NH}_{4} \mathrm{Cl}$ has reversed NPQ in all cases. Still, the relaxation time remained to be dependent upon the extent of quenching. The effects of $\mathrm{NH}_{4} \mathrm{Cl}$ on the slow reversal of NPQ in diatoms are rather consistent with the NPQ model described by Horton and Ruban for higher plants (Horton and Ruban, 1992). The model suggests a gradual conformational transition within the LHCII antenna into the quenching state. The key element of this change is zeaxanthin, which acts as an allosteric controller. Zeaxanthin analogue, DT, has most likely a similar function in diatoms. One would predict that 
the structure of their antenna is capable of a conformational change favouring transition into a very efficient energy-dissipative state. A recent paper on thermodynamics of the fluorescence quenching in isolated LHCII antenna supports this view and suggests that the oligomerisation state of antenna is one of the factors controlling dynamics of the complex together with zeaxanthin, protonation and domain structure (Wentworth et al., 2003). The general NPQ formation scenario may involve the following sequence of events: formation of DT and protonation of antenna, cooperative conformational transition of the latter into the quenching state involving partitioning of DT into the more hydrophobic regions and more hydrophobic dislocation of proton-binding domains. This should serve as an NPQ 'lock', preventing a quick relaxation in the absence of a bulk proton gradient. The clear evidence of the co-operative manner of NPQ formation is a progressive distinct sigmoidicity of the fluorescence relaxation curve with an increase of the extent of quenching (compare Figure 3A, traces 2 - 6).

\section{Relationship between super-NPQ and $q P$}

Diatoms grown under intermittent light regime possess particularly large levels of energy dissipation (Lavaud et al., 2002a). At this light environment diatoms possess very low photosynthetic rate. Indeed, as was mentioned earlier, the PSII saturating light intensity for Phaeodactylum is about 4 times less than that for Arabidopsis leaves. A large percentage of PSII reaction centers have to be closed before the photoprotective NPQ can be activated. Figure 5 illustrates this observation showing relationship between $\mathrm{qP}$ and NPQ in plants and diatoms. In higher plants this relationship seems to be almost linearly reciprocal. Photoprotection is closely following the PSII redox-state. In diatoms grown at intermittent light regime 
relationship between $\mathrm{qP}$ and NPQ is rather hyperbolic. It looks like these two processes can be relatively independent. The adaptation of Phaeodactylum to this rather unusual light regime is such that NPQ is standing-by and can be readily triggered only when the PSII redox-state is very close to saturation. It is likely that some additional sources of protons are required here to trigger NPQ. Those could originate, for example, from the cyclic electron transport around PSI, which is activated when the linear electron transport is saturated (Caron at al., 1987). This is coherent with the recent finding on Arabidopsis mutant lacking the protein controlling the PSI cycle (Munekage et al, 2002). NPQ in this mutant is significantly reduced suggesting the important role of protons generated by PSI in controlling the energy dissipation in PSII antenna. Therefore the apparent absence of coordination between NPQ and PSII electron transfer activity is an illustration of the relative independence of the PSII redox-state from the proton-motive electron transfer and subsequently NPQ.

\section{Comparison of the absorption changes associated with NPQ in diatoms and plants}

Illumination of diatom cells induces significant absorption changes in the carotenoid region. Figure 6A shows spectra of dark-adapted and illuminated samples. The distinct maximum around $490 \mathrm{~nm}$ in the spectrum of dark-adapted cells is strongly decreased and a shoulder above $500 \mathrm{~nm}$ emerges after illumination. Calculation of a difference spectrum illuminated-minus-dark revealed a major maximum at $512 \mathrm{~nm}$ and a minimum at $490 \mathrm{~nm}$ corresponding to DT-minus-DD spectrum (Figure 6B, trace 1). The similar absorption difference spectrum for the violaxanthin cycle, zeaxanthinminus-violaxanthin is shown as a dotted line (Figure 6B). Although, both zeaxanthin and DT have the same number of conjugated double bonds, DT absorption is $4 \mathrm{~nm}$ 
red-shifted comparing to zeaxanthin. Interestingly the similar difference spectrum for the isolated LHC antenna complex from Phaeodactylum thylakoids has $508 \mathrm{~nm}$ maximum instead of $512 \mathrm{~nm}$ and the positive DT band is much narrower (Figure 6B, trace 2, see also (Lavaud et al., 2003)). This suggests that the environment of DT in the intact thylakoid membrane is different from that of the isolated complex, likely due to tighter interaction within hydrophobic antenna domains of high polarisability. The difference spectrum cells-minus-LHC represents the additional absorption change in the xanthophyll region under conditions of NPQ (Figure 6B, trace 3).

Another key difference between spectra 1 and 2 of Figure 6B is the presence of a strong $690 \mathrm{~nm}$ band in chlorophyll $a$ region, which is similar to that observed in higher plant thylakoids when NPQ was formed (Ruban et al., 1992). This band was found to be present only when the fluorescence quenching in isolated LHCII was induced. Although the work is in progress to understand the nature of this band, it is likely to originate from chlorophyll-chlorophyll or chlorophyll-xanthophyll association in the quenching locus.

To separate the xanthophyll cycle-associated from NPQ-dependent absorption changes an uncoupler $\mathrm{NH} 4 \mathrm{Cl}$ was employed. Figure 6C, traces 1 and 2, represent the absorption changes in the blue and red regions due to addition of $\mathrm{NH} 4 \mathrm{Cl}$ and rapid removal of NPQ. In the red region the $690 \mathrm{~nm}$ positive band was similar to that in the spectrum 1, Figure 6B. The main maximum in the xanthophyll region is even more red-shifted towards $514 \mathrm{~nm}$ and the band is $4 \mathrm{~nm}$ broader than that in the difference spectrum 1 of the Figure 6B. As was stated above, during the uncoupler treatment a partial DT epoxidation process took place. This could cause the presence of the DTminus-DD component at $508 \mathrm{~nm}$ in the uncoupler-induced spectral change. Therefore, 
the subtraction of this component using the deepoxidation difference spectrum for LHC from the uncoupler-induced difference spectrum reveals purely protonationdependent change (Figure 6C, trace 3). The latter has the same maximum as the spectrum 3 from the Figure $6 \mathrm{~B}$ but it is dominating in the uncoupler-dependent spectrum. The NPQ-associated absorption band at $522 \mathrm{~nm}$ in diatoms is analogous to that in higher plants at $535 \mathrm{~nm}$ (Figure 6C, dotted trace). This band was found to be zeaxanthin-dependent and recently has been assigned to the special, activated state of zeaxanthin into NPQ locus, probably associated with PsbS protein - a key trigger of NPQ in plants (Ruban et al., 2002a, Aspinal-O'Dea et al., 2002). The strong absorption shift of almost $25 \mathrm{~nm}$ was attributed to a zeaxanthin dimer. It was postulated to be a head-to- tail type of dimer. In analogous spectrum of diatoms 522 $\mathrm{nm}$ band could represent the activated DT. However the red shift (around $10 \mathrm{~nm}$ ) is much smaller than in the higher plant spectrum. This is possibly because DT is very asymmetric compared to zeaxanthin and conjugation of optical $\pi$-electrons extends only into one end-group (Figure 7) it is less probable that it can form dimers with similar optical properties to zeaxanthin. It is also possible that because of likely differences of plant and diatom antenna structures, DT environment in the NPQ locus is very different from that of zeaxanthin. These implications will be tested in a near future for the LHC of diatoms by biochemical work and spectroscopic approaches developed for higher plants (Ruban et al., 1999, 2001, 2002a, 2002b).

\section{Direct measurement of the NPQ and diatoxanthin formation kinetics}

Using HPLC determination of DT, a point-by-point correlation close to linear was observed between DT and NPQ (Lavaud et al., 2002a, Lavaud et al., 2002b). A more precise determination of the relationship between NPQ and the different absorption 
peaks attributed to the xanthophyll cycle was done in simultaneous kinetic measurements as was performed on higher plant leaves (Ruban et al., 1993). Figure 8A shows kinetics of chlorophyll fluorescence at $F_{m}$ level and absorption at $514 \mathrm{~nm}$ induced by saturating light. The kinetic of fluorescence quenching was found to follow hyperbolic function similarly to that of spinach chloroplasts and leaves (Ruban and Horton, 1999). This observation is yet another evidence of the fundamental resemblance between the energy dissipation mechanism in diatoms and plants. NPQ was in linear correlation with the appearance of the $522 \mathrm{~nm}$ band, which, as hypothesised above, may reflect an activated, partitioned into the hydrophobic quenching locus DT (Figure 8, B). Clear deviation from linearity can be observed in correlation of NPQ with absorption change in more short-wavelength region at 514 $\mathrm{nm}$. This observation could provide another support to the idea that a sub-population of DT molecules in diatoms, as zeaxanthin in plants, undergoes incorporation into the NPQ locus. The red shifted peak is indicative of either a direct fluorescence quencher or/and a state of allosteric activator of the quenching, promoting conformational change within the antenna.

\section{Factors controlling the extent of $N P Q$}

The results mentioned above indicate tight but not direct relationship between DT and NPQ. After $1 \mathrm{hr}$ of light treatment we have found that only $65 \%$ of DD was converted into DT. This is about the same as was obtained during illumination of spinach leaves (Ruban and Horton, 1999). However in spite of a similar extent of deepoxidation the differences in NPQ are large. Moreover the low-pH induced deepoxidation of isolated thylakoids from Phaeodactylum cells is reaching $80 \%$, which is similar to that reported for spinach (Ruban et al., 1999). Therefore these 
diatoms have very much the same maximum de-epoxidation capacity as higher plants. The super-NPQ ( 8 - 15 for diatoms against 2 - 3 for Arabidopsis and spinach) can be due to the larger xanthophyll pool size in diatoms grown under intermittent light while the antenna size remains the same than for algae grown under a classical light/dark regime. For a smaller pool size associated with the same antenna size, smaller values of NPQ are obtained closer to the values found in higher plants (Lavaud et al., 2002a, 2003). In P. tricornutum Lavaud et al. (Lavaud et al., 2003) have shown that the additional DD molecules of intermittent light grown cells are mainly associated with LHC fraction. Recent experiments on Arabidopsis indicate that doubling of amount of xanthophyll cycle carotenoids in PSII antenna had no visible effect on the maximum NPQ (Davison et al., 2002). Therefore these contradicting observations could probably be explained by differences in the concentration of quenching centers in the two antenna systems. The proportion of activated DT in the NPQ locus can be larger than that of the activated zeaxanthin. Indeed, judging from the absorption difference spectra shown on the Figure $6 \mathrm{~B}$ and $\mathrm{C}$, the amplitude of NPQ-associated change at $522 \mathrm{~nm}$ in diatoms is reaching $25-30 \%$ of the total DT absorption, whereas the absorption at $535 \mathrm{~nm}$ is about only $10 \%$ of the total zeaxanthin absorption.

The role of PsbS protein - a likely antenna associate - has been in a center of recent mechanistic research on NPQ in plants (Li et al., 2002a, 2002b, 2002c, AspinalO'Dea et al., 2002). The amount of this protein was shown to correlate closely with the extent of the fluorescence quenching in vivo (Li et al., 2002c). However so far the presence of PsbS in diatoms has not been shown but a complex with a similar role could be present and its concentration could be increased by intermittent light regime 
together with the increase of the DD pool size while the antenna size remained constant. It is clear that the next step in the investigation of the NPQ mechanism in diatom algae should be concentrated on the biochemical, biophysical and molecular biological studies of the PSII complexes involved.

\section{Conclusions}

Super-NPQ in diatom alga Phaeodactylum tricornutum is closely related to DT concentration. Parallel measurements of NPQ and DT absorption kinetics suggest indirect involvement of this xanthophyll in the fluorescence quenching process. The fast reversible phase of NPQ as well as the $535 \mathrm{~nm}$ absorption band are absent in this alga. Fluorescence quenching was found to correlate closely with the absorption change at $522 \mathrm{~nm}$. This band is hypothesised to belong to an activated DT interacting with the NPQ locus in antenna. The hyperbolic type of the fluorescence quenching and gradual co-operative character of NPQ formation are the most fundamental common features of the mechanisms of the excess energy dissipation in diatoms and plants. Due to the low photosynthetic rates and danger of a sudden exposure to excess light NPQ in diatoms can be significantly higher than that in plants and shows more sustained character. The causes of a large NPQ in diatoms could originate from the unique organisation and dynamic properties of light-harvesting antenna components, affinity of a DT binding into the quenching locus and structural properties of this xanthophyll.

\section{Acknowledgements}


AVR thanks administration of the Ecole Normale Superieure for invited Professorship and CNRS for a visiting Fellowship during the summer-autumn 2002. JL was supported by the University of Paris VI. This work is supported by UK BBSRC.

\section{References}

Arsalane W, Rousseau B, Duval JC (1994) Influence of the pool size of the xanthophyll cycle on the effects of light stress in a diatom - competition between photoprotection and photoinhibition. Photochem Photobiol 60: 237-243

Aspinall-O’Dea M, Wentworth M, Pascal A, Robert B, Ruban AV, Horton P (2002) The PsbS subunit of photosystem II binds zeaxanthin and activates it for nonphotochemical fluorescence quenching. Proc. Natl. Acad. Sci USA 99: 16331-16335

Barber J (1995) Molecular basis of the vulnerability of photosystem-II to damage by light. Australian Journal of Plant Physiology 22: 201-208

Caron L, Berkaloff C, Duval J-C, Jupin H (1987) Chlorophyll fluorescence transients from the diatom Phaeodactylum tricornutum: relative rates of cyclic phosphorylation and chlororespiration. Photosynthesis Res 11: 131-139

Casper-Lindley C, Bjorkman O (1998) Fluorescence quenching in four unicellular algae with different light-harvesting and xanthophyll cycle pigments. Photosynth Res 56: $277-289$

Davison PA, Hunter CN, Horton P (2002) Overexpression of beta-carotene hydroxylase enhances stress tolerance in Arabidopsis. Nature 418: 203-206 
Demmig-Adams B (1990) Carotenoids and photoprotection in plants - a role for the xanthophyll zeaxanthin. Biochim Biophys Acta 1020: 1-24

Demmig-Adams B, Adams WW III (1992) Photoprotection and other responses of plant to high light stress. Annu Rev Plant Physiol Plant Mol Biol 43: 599-626

Field, CB, Behrenfeld MJ, Randerson JT, Falkowski P (1998) Primary production of the biosphere: integrating terrestrial and oceaniccomponents. Sciense 281: 237-240

Frank HA, Cua A, Chinwat V, Young A, Gosztola D, Wasielewski MR (1994) Photophysics of the carotenoids associated with the xanthophyll cycle in photosynthesis. Photosynth Res 41, 389-395

Gilmore AM (1997) Mechanistic aspects of xanthophyll cycle-dependent phtoprotection in higher plant chloroplasts and leaves. Physiol Plantarum 99: 19-209

Hager A, Stransky H (1970) Das carotinoidmuster und die verbreitung des lichtinduzieren xanthophyllcyclus in verschiedenen algenklassen. V. Einzelne vertreter der Cryptophyceae, Euglenophyceae, Bacillariophyceae, Chrysophyceae und Phaeophyceae. Arch. Mikrobiol., 73, 77-89.

Horton P, Ruban AV (1992) Regulation of photosystem-II. Photosynthesis Research 34: $375-385$

Horton P, Ruban AV, Wentworth M (2000) Allosteric regulation of the lightharvesting system of photosystem II. Phil Trans R Soc Lond B 355: 1361-1370

Horton P, Ruban AV, Walters RG (1996) Regulation of light harvesting in green plants. Annu Rev Plant Physiol Plant Mol Biol 47: 655-684 
Jakob T, Goss R, Wilhelm C (1999) Activation of diadinoxanthin de-epoxidase due to a chlororespiratory proton gradient in the dark in the diatom Phaeodactylum tricornutum. Plant Biol 1, 76-82

Krause GH, Weis E (1991) Chlorophyll fluorescence and photosynthesis: the basics. Annu Rev Plant Physiol Plant Mol Biol 42: 313-349

Lavaud J, Rousseau B, van Gorkom HJ, Etienne A-L (2002a) Influence of the diadinoxanthin pool size on the photoprotection in marine planktonic diatom Phaeodactylum tricornutum. Plant Physiol 129: 1398-1406

Lavaud J, Rousseau B, Etienne A-L (2002b) In diatoms, a transthylakoid proton gradient alone is not sufficient to induce a non-photochemical fluorescence quenching. FEBS Lett 523: 163-166

Lavaud J, Rousseau B, Etienne A-L (2002c) Photosystem II electron transfer cycle and chlororespiration in planktonic diatoms. Photosynthesis Res 74, 51-59

Lavaud J, Rousseau B, Etienne A-L (2003) Enrichment of the light-harvesting complex in diadinoxanthin and implications for the nonphotochemical fluorescence quenching in diatoms. Biochemistry 42, 5802-5808

Li XP, Bjorkman O, Shih C, Grossman AR, Rosenquist M, Jansson S, Niyogi K (2000) A pigment-binding protein essential for regulation of photosynthetic light havesting. Nature 403: 391-395

Li XP, Phippard A, Pasari J, Niyogi K (2002a) Structure-function analysis of photosystem II subunit S (PsbS) in vivo. Functional Plant Physiology 29: 1131-1139 
Li XP, Muller-Moule P, Gilmore AM, Niyogi K (2002b) PsbS-dependent enhancement of feedback de-excitation protects photosystem II from photoinhibition. Proc. Natl. Acad. Sci USA 99: 15222-15227

Li XP, Gilmore AM, Niyogi KK (2002c) Molecular and global time-resolved analysis of a psbS gene dosage effect on $\mathrm{pH}-$ and xanthophyll cycle-dependent nonphotochemical quenching in photosystem II. J Biol Chem 277: 33590-33597

Munekage Y, Hojo M, Meurer J, Endo T, Tasaka M, Shikanai T (2002) PGR5 is involved in cyclic electron flow around photosystem $\mathrm{I}$ and is essential for photoprotection in Arabidopsis. Cell 110: 361-371

Niyogi K (1999) Photoprotection revisited: genetic and molecular approaches. Annu Rev Plant Physiol Plant Mol Biol 50: 333-359

Olaizola M, Laroche J, Kolber Z, Falkowski PG (1994) Non-photochemical fluorescence quenching and the diadinoxanthin cycle in a marine diatom. Photosynth Res 41: 357-370

Osmond B (1981) Photorespiration and photoinhibition. Some implications for the energetics of photosynthesis. Biochim Biophys Acta 639: 77-98

Owens TG, Shreve AP, Albrecht AC (1992) Dynamics and mechanism of singlet energy transfer between carotenoids and chlorophylls: light harvesting and nonphotochemical fluorescence quenching. In Research in Photosynthesis, vol. 4, ed. N Murata, pp.179-186 Dordrecht, The Netherlands: Kluwer 
Rees D, Young A, Noctor G, Britton G, Horton, P (1989) Enhancement of the $\Delta \mathrm{pH}-$ dependent dissipation of excitation energy in spinach chloroplasts by light-activation: correlation with the synthesis of zeaxanthin. FEBS Lett 256: 85-90

Ruban AV, Rees D, Pascal A, Horton P (1992) Mechanism of $\Delta \mathrm{pH}$-dependent dissipation of absorbed excitation energy by photosynthetic membranes. II. The relationship between LHCII aggregation in vitro and $\mathrm{qE}$ in isolated thylakoids. Biochim Biophys Acta 1102: 39-44.

Ruban AV, Young AJ, Horton P (1993) Induction of nonphotochemical energydissipation and absorbency changes in leaves - evidence for changes in the state of light harvesting system of photosystem II in vivo. Plant Physiol 102, 741-750

Ruban AV, Horton P (1995) An investigation of the sustained component of nonphotochemical quenching of chlorophyll fluorescence in isolated chloroplasts and leaves of spinach. Plant Physiol 108, 721-726

Ruban AV, Horton P (1999) The xanthophyll cycle modulates the kinetics of nonphotochemical energy dissipation in isolated light-harvesting complexes, intact chloroplasts and leaves of spinach. Plant Physiol 119, 531-542

Ruban AV, Lee PJ, Wentworth M, Young AJ, Horton P (1999) Determination of the stoichiometry and strength of binding of xanthophylls to the photosystem II light harvesting complexes. 274: 10458-10465.

Ruban AV, Pascal AA, Robert B., Horton P (2001) Configuration and dynamics of carotenoids in light-harvesting antennae of the thylakoid membrane. J Biol Chem: 276: $24862-24870$ 
Ruban AV, Pascal AA, Robert B, Horton P (2002a) Activation of zeaxanthin is an obligatory event in the regulation of photosynthetic light harvesting. J Biol Chem: $277,7785-7789$

Ruban AV, Pascal AA, Lee PJ, Robert B, Horton P (2002b) Molecular Configuration of Xanthophyll Cycle Carotenoids in Photosystem II Antenna Complexes. J Biol Chem: 277, 42937-42942

Smetacek VA (1999) Diatoms and the ocean carbon cycle. Protist 150: 25-32

Ting CS, Owens TG (1993) Photochemical and non-photochemical fluorescence quenching processes in the diatom Phaeodactylum tricornutum. Plant Physiol 101: $1323-1330$

Tréguer P, Nelson DM, vanBennekom AJ, DeMaster DJ, Leynaert A, Quéginer B (1995) The silica balance in the world ocean: a reestimate. Science 269: 375-379

Verhoeven AS, Adams WW, Demmig-Adams B (1998) Two forms of sustained xanthophyll cycle-dependent energy dissipation in overwintering Euonymus kiautschovicus. Plant Cell and Environment 21: 893-903

Wentworth M, Ruban AV, Horton P (2003) Thermodynamic investigation into the mechanism of the chlorophyll fluorescence quenching in isolated photosystem II light-harvesting complexes. J Biol Chem, in press. 


\section{Figure legends}

Figure 1. Fluorescence quenching in cells of Phaeodactylum tricornutum (A) and Arabidopsis taliana leaves (B) induced by the saturating actinic light intensity. $\mathrm{P}-$ saturating pulse; $\mathrm{AL}$ - continuous light on $\left(400\right.$ and $2000 \mu \mathrm{Mm}^{-2} \mathrm{~s}^{-1}$ for Phaeodactylum and Arabidopsis respectively). Chlorophyll concentration of cells was $20 \mu \mathrm{M}$. Sample was constantly stirred at $18^{\circ} \mathrm{C}$.

Figure 2. Reversibility of the NPQ level in Phaeodactylum tricornutum cells after actinic light treatment of varying duration. Illumination was followed by 5 min of dark recovery prior the measurement of the fluorescence level and calculation of NPQ. Light intensity and chlorophyll concentration as in experiments shown on Figure 1. Open circles: total NPQ after illumination. Closed circles: NPQ reversed after 5 min of dark adaptation. Closed triangles: uncoupler-dependent NPQ, reversed by addition of uncoupler $\mathrm{NH}_{4} \mathrm{Cl}$.

Figure 3. Fluorescence traces showing the uncoupler-dependent reversibility of NPQ in cells of Phaeodactylum tricornutum (A) and intact spinach chloroplasts (B). A: trace $1,100 \mathrm{mM}$ of uncoupler $\mathrm{NH}_{4} \mathrm{Cl}$ was added 1 min before continuous illumination; traces $2-6$, addition of $\mathrm{NH}_{4} \mathrm{Cl}$ during varying stages of the fluorescence quenching formation. Light intensity and chlorophyll concentration as in experiments shown on Figure 1. Numbers above traces indicate values of NPQ reversed by uncoupler.

Figure 4. Relationship between the amplitude of NPQ and time required to recover $50 \%$ of quenching by addition of uncoupler $\mathrm{NH}_{4} \mathrm{Cl}$. 
Figure 5. Relationship between photochemical (qP) and nonphotochemical (NPQ) fluorescence quenching in Arabidopsis taliana leaves (closed circles) and Phaeodactylum tricornutum cells (open squares). Different levels of qP and NPQ were obtained by using a range of actinic light intensities varying from 30 to 2500 $\mu \mathrm{M}^{-2} \cdot \mathrm{s}^{-1}$. For calculation of quenching parameters see Materials and Methods.

Figure 6. A. Room temperature absorption spectra of dark-adapted (Dark) and lighttreated (Illuminated) Phaeodactylum tricornutum cells. For details of illumination see Materials and Methods. B. 1, difference spectrum illuminated-minus-dark adapted cells; 2, difference between absorption spectrum of LHC preparation from Phaeodactylum thylakoids enriched in DT minus the absorption spectrum of LHC preparation enriched in DD; 3, difference 1-2 spectrum; dotted line, difference between spectra of Arabidopsis leaf containing zeaxanthin and leaf containing violaxanthin. C. 1 and 2, two regions of uncoupler-induced difference spectrum of algae cells illuminated for $1 \mathrm{~min} ; 3$, difference between spectrum 1 and spectrum 2 from B; dotted line - NPQ-associated absorption spectrum of Arabidopsis leaf.

Figure 7. Structural formulae of zeaxanthin and diatoxanthin.

Figure 8. A. Simultaneous kinetics of chlorophyll fluorescence quenching (open symbols) and A514 band formation (closed symbols) in Phaeodactylum tricornutum cells. Solid line is a single hyperbolic fit of the fluorescence kinetic (as in Ruban and Horton, 1999). B. Relationship between NPQ and extent of absorption changes at 514 (closed circles) and $522 \mathrm{~nm}$ (open squares). For details of illumination see Materials and Methods. 
Figure 1

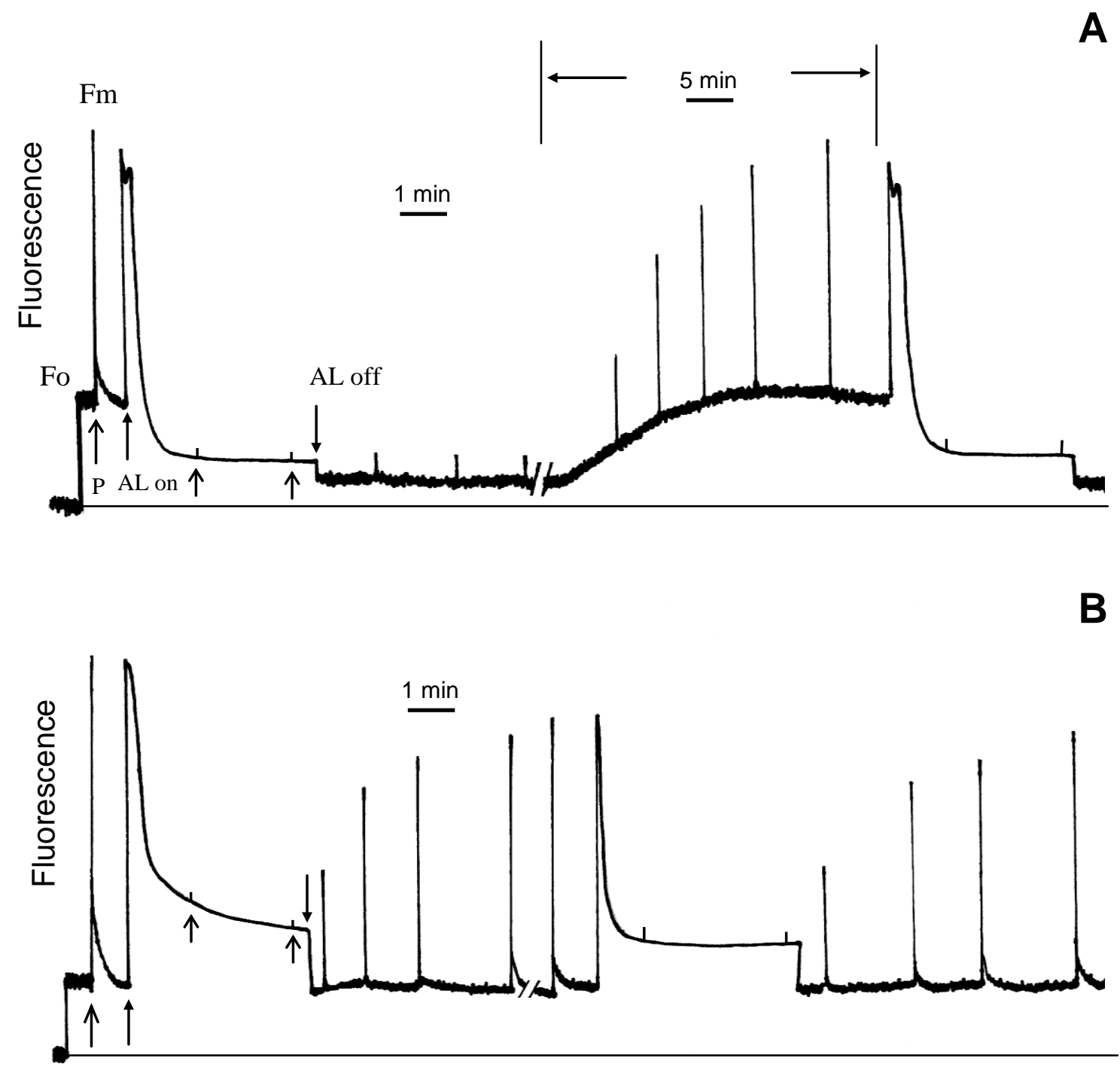


Figure 2

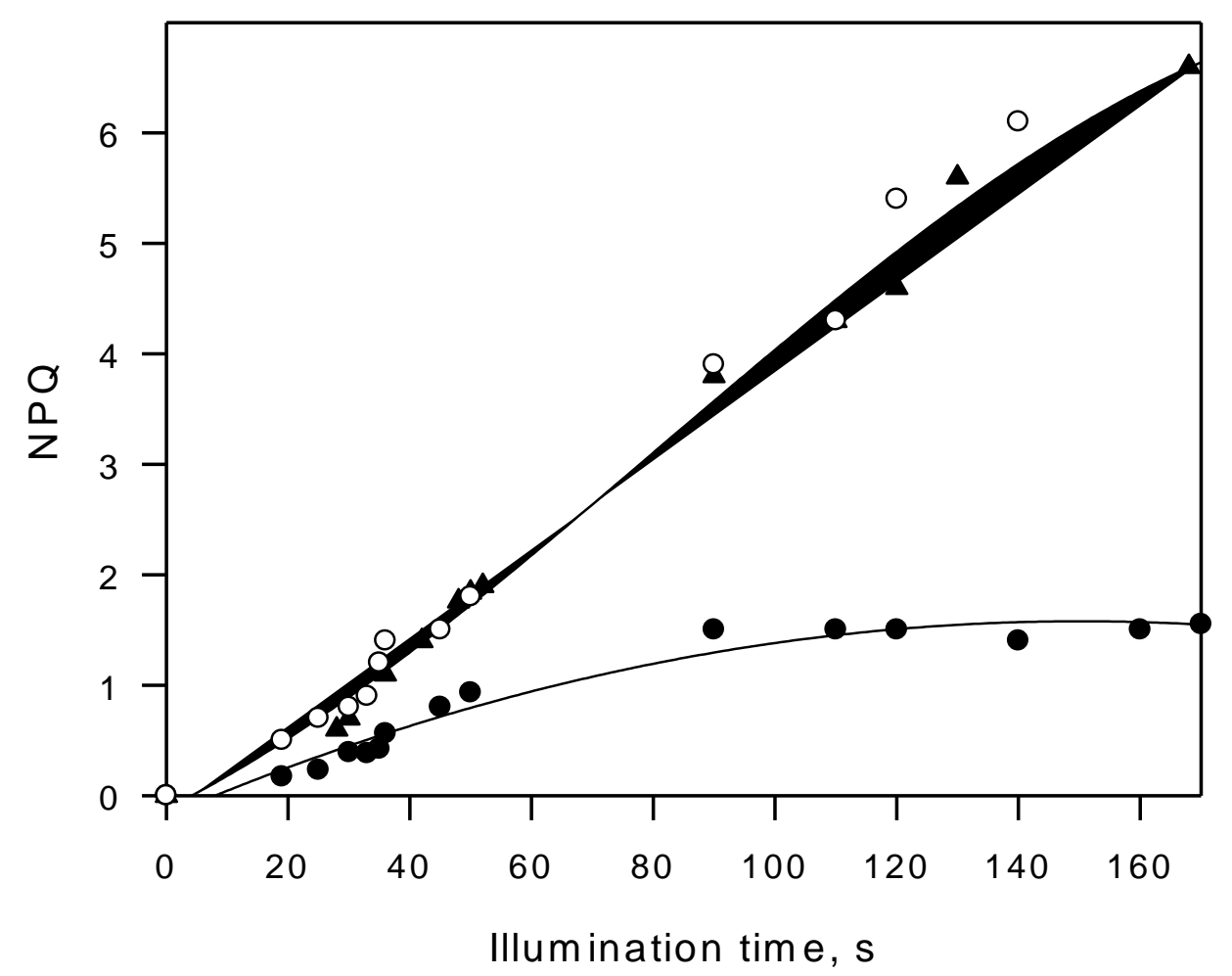


Figure 3

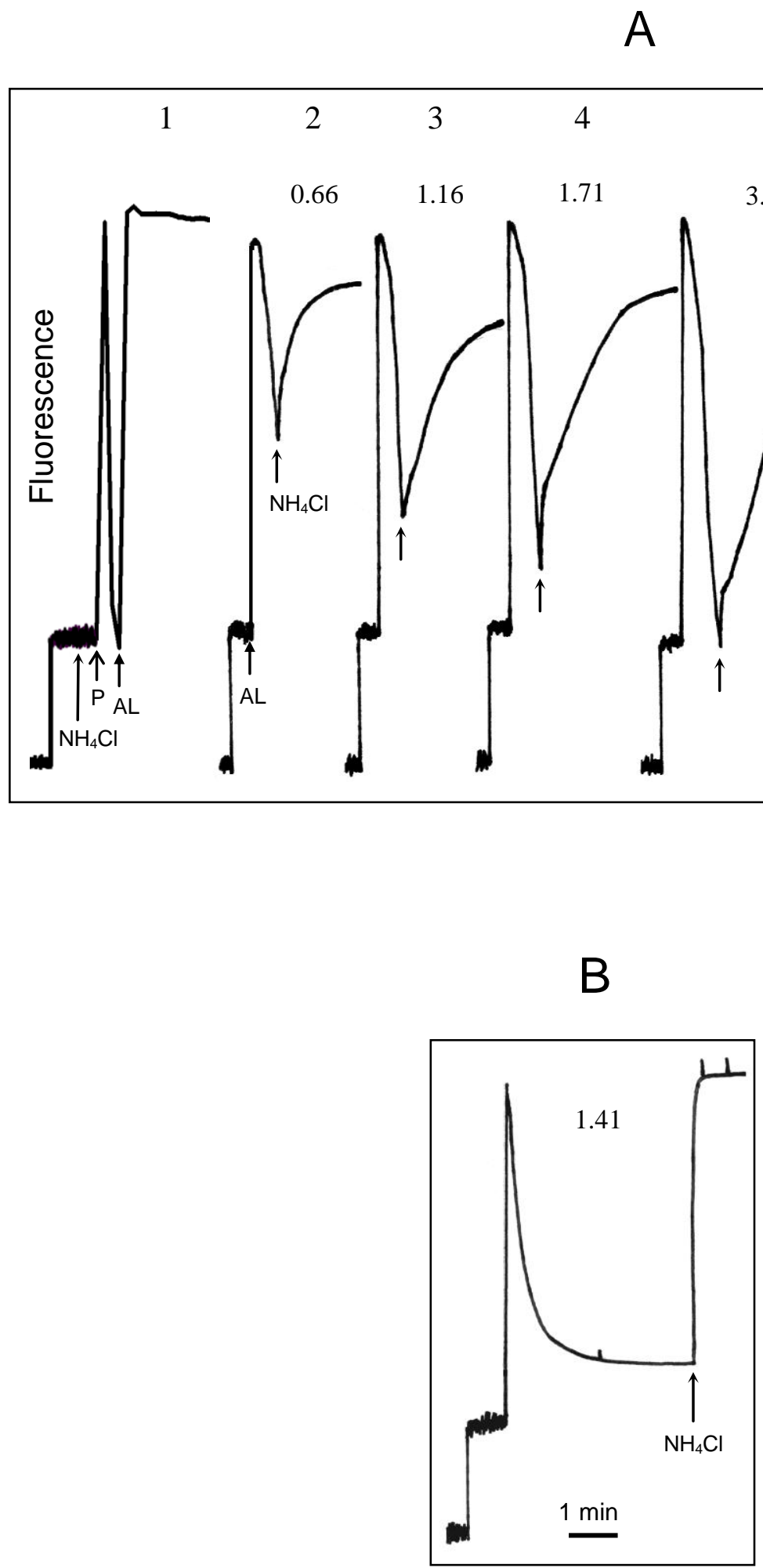


Figure 4

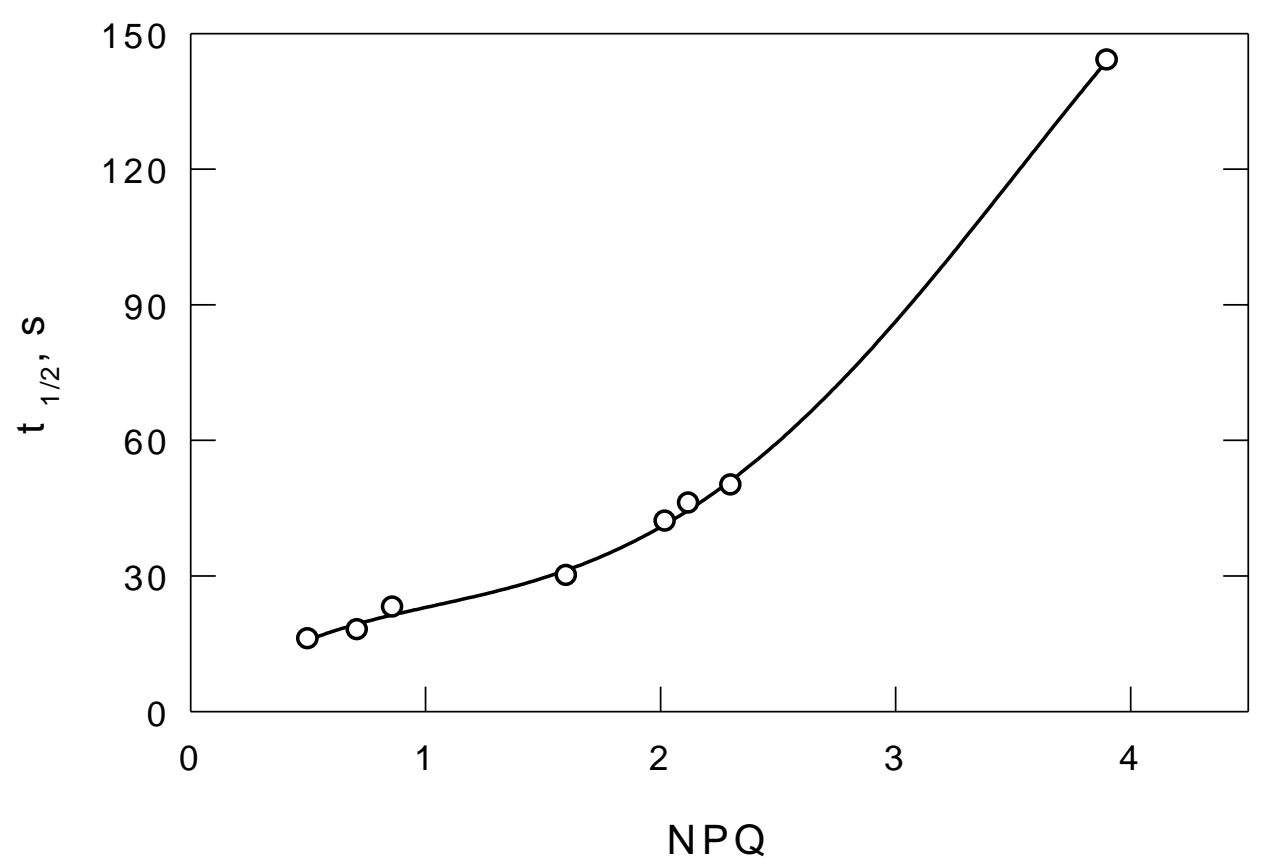


Figure 5

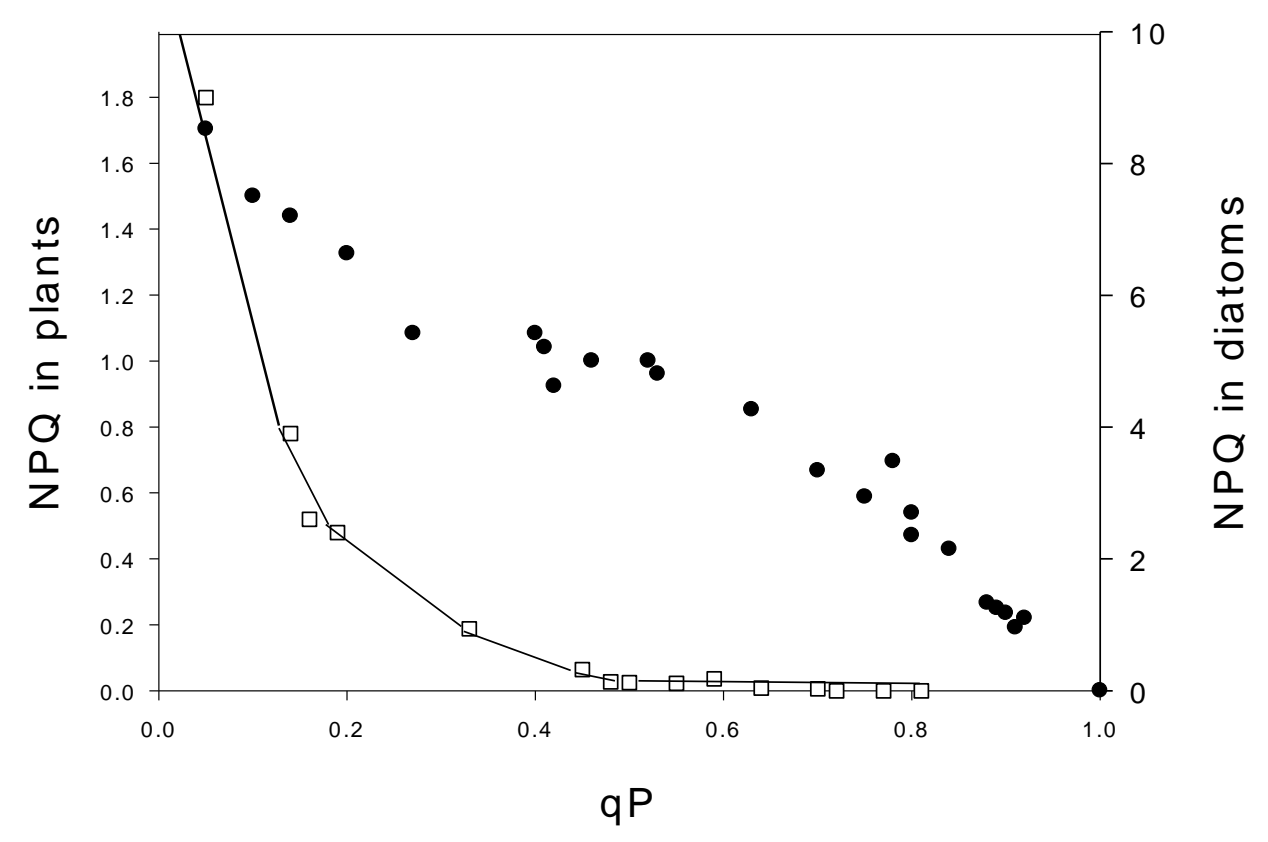


Figure 6
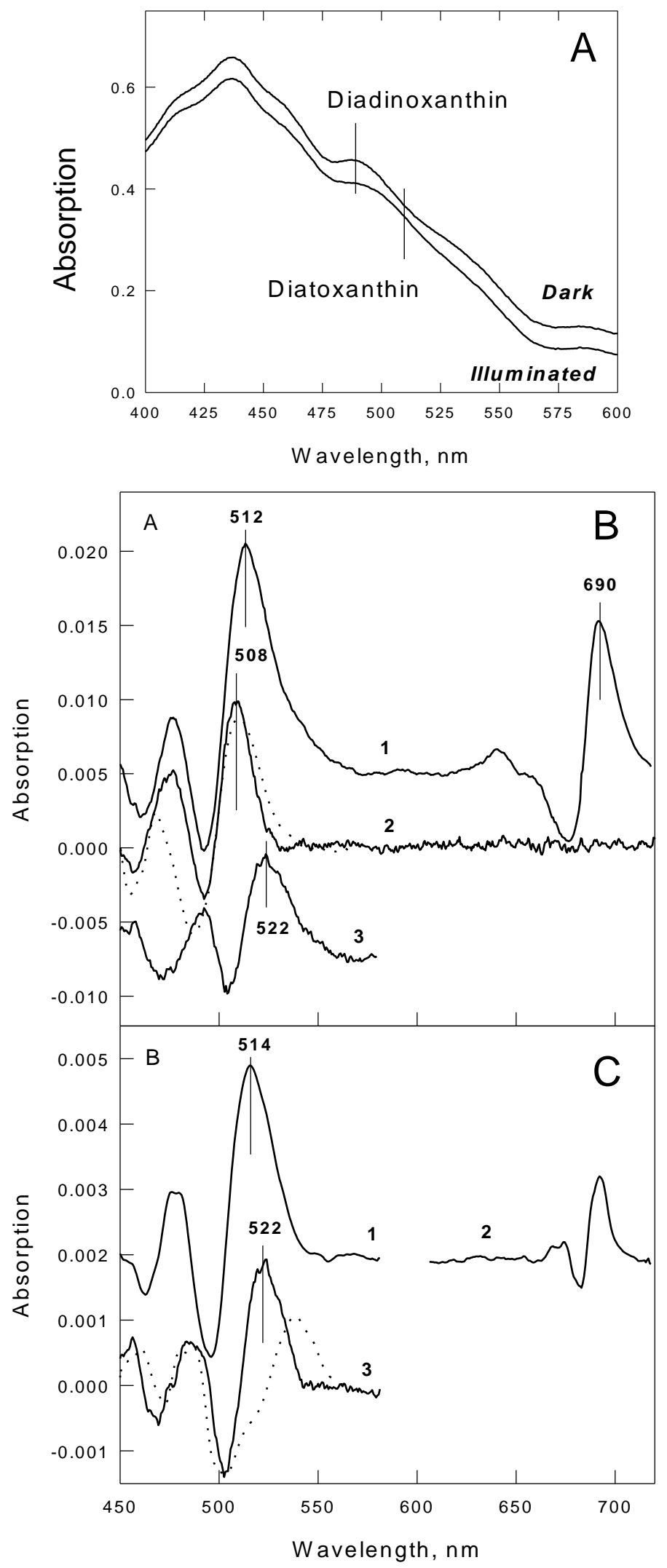
Figure 7
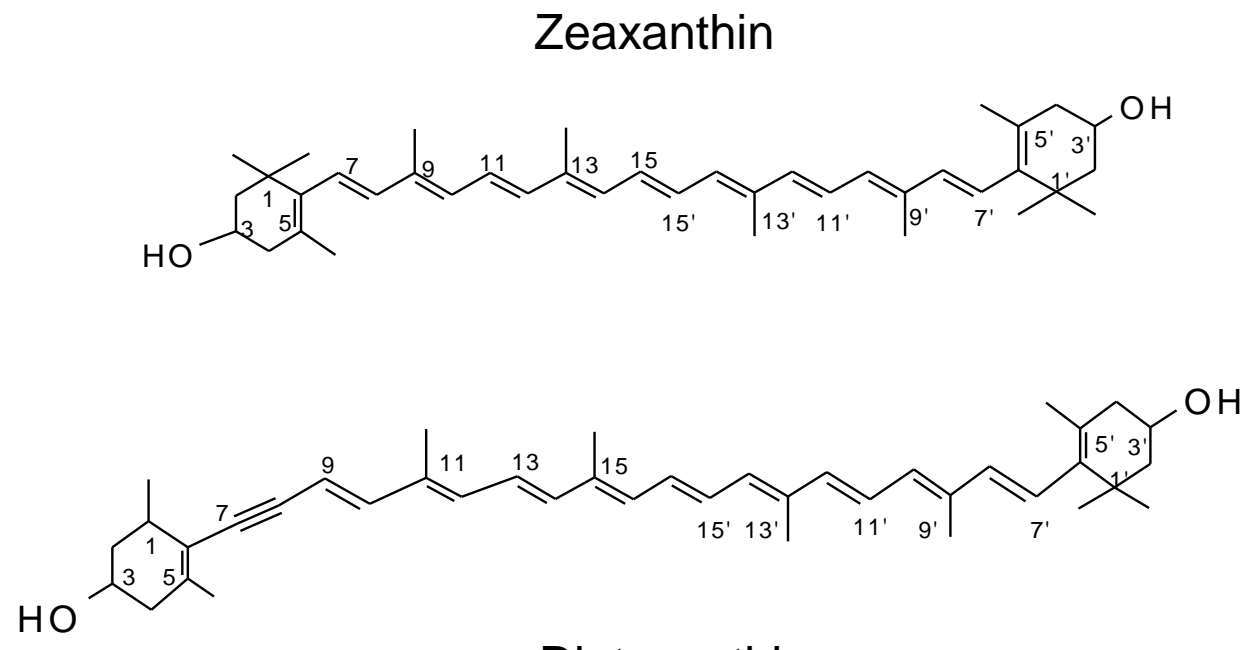

Diatoxanthin 
Figure 8.
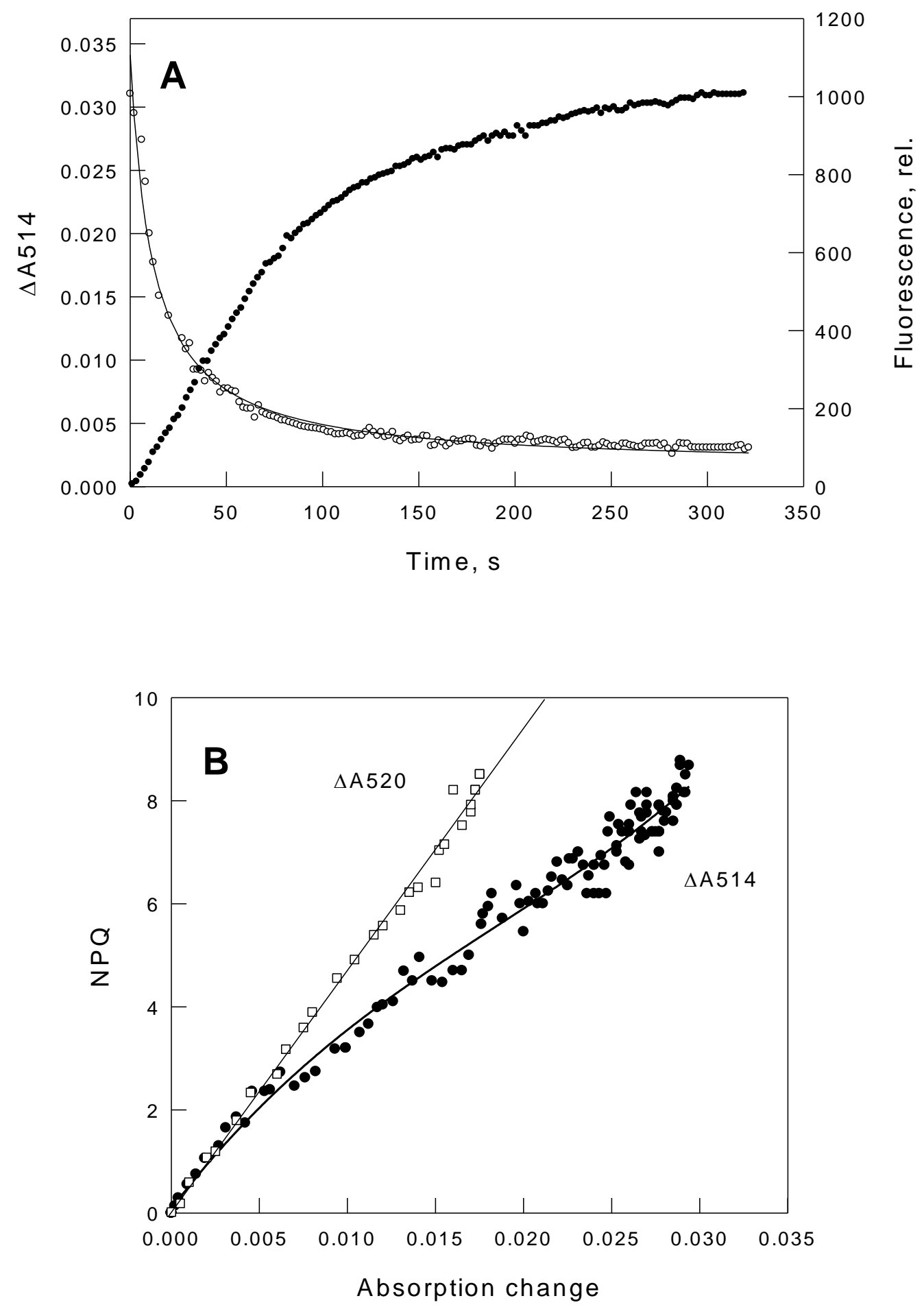